\title{
A qualidade da informação contábil e a precificação do retorno em excesso no mercado brasileiro de capitais
}

Earnings quality and pricing of excess return in the brazilian capital market

Calidad de la información contable y precios de retorno del exceso en el mercado de capitales brasileño

\section{Filipe Coelho de Lima Duarte}

Mestrando no PPGCC Universidade Federal da Paraíba (UFPB)

Graduado em Ciências Atuariais pela Universidade Federal da Paraíba (UFPB)

Endereço: Centro de Ciências Sociais Aplicadas, Campus I, Cidade Universitária, CEP: 58.051-900. João Pessoa/PB, Brasil

E-mail: filipe_pb_duarte@hotmail.com

\section{Wenner Glaucio Lopes Lucena}

Doutor em Ciências Contábeis pelo Programa Multiinstitucional e Inter-Regional de Pós-

Graduação em Ciências Contábeis UnB/UFPB/UFRN

Professor no Programa de Pós-Graduação em Ciências Contábeis da Universidade Federal da Paraíba (UFPB)

Endereço: Centro de Ciências Sociais Aplicadas, Campus I, Cidade Universitária, CEP: 58.051-900. João Pessoa/PB, Brasil

Telefone: +55 (83) 3216-7285

E-mail:wdlucena@yahoo.com.br

Artigo recebido em 25/12/2016. Revisado por pares em 08/05/2018. Reformulado em 08/06/2018. Recomendado para publicação em 15/06/2018 por Carlos Eduardo Facin Lavarda Editor-Chefe). Publicado em 30/06/2018. 


\section{Resumo}

Este trabalho se fundamenta na análise da relação e magnitude entre a qualidade da informação contábil e o spread do retorno em excesso. Utilizou-se, como métrica para retorno esperado, do custo de capital implícito dos crescimentos dos lucros fundamentada em Botosan e Plumlee (2005). Com uma amostra de 300 empresas listadas na $B^{3}$ entre 2005 e 2014 foram aplicadas as seguintes medidas de qualidade da informação contábil: persistência, previsibilidade, accruals anormais, coeficiente resposta de resultado e value relevance com vistas a investigar se elas possuem diferenças na capacidade de explicar o spread do retorno em excesso. Os resultados mostraram que todas as medidas de qualidade da informação contábil, exceto value relevance e accruals anormais, se associaram negativamente com o spread do retorno em excesso. Além disso, os accruals anormais foram as métricas que melhor apresentaram capacidade em representar a má-precificação das ações. Portanto, como implicação prática, o presente estudo aponta para os accruals anormais como as medidas da qualidade da informação contábil que melhor observam a assimetria informacional na precificação das ações constantes na $\mathrm{B}^{3}$.

Palavras chave: Qualidade da Informação Contábil. Retorno em Excesso. Custo de Capital.

\section{Abstract}

This paper is based on the analysis of the relation and magnitude between Earnings Quality and the spread of excess return. As a metric for expected return, we used the implicit capital cost of earnings growth based on Botosan and Plumlee (2005). With a sample of 300 companies listed in B3 between 2005 and 2014, the following measures of Earnings Quality were applied: persistence, predictability, abnormal accruals, coefficient of response of result and value relevance in order to investigate if they have differences in the capacity to explain the spread of excess return. The results showed that all measures of Earnings Quality, except value relevance and abnormal accruals, were negatively associated with the spread of excess return. In addition, the abnormal accruals were the metrics that were better represents the mis-pricing of stocks. Therefore, as a practical implication, the present study points out to abnormal accruals such as measures of the Earnings Quality that best observe the information asymmetry in the pricing of the actions in $B^{3}$.

Keywords: Earnings Quality. Excess Return. Cost of Capital.

\section{Resumen}

Este documento se basa en el análisis de la relación y la magnitud entre la calidad de la información contable y la spread del exceso de rendimiento. Como una métrica para el rendimiento esperado, utilizamos el costo de capital implícito del crecimiento de las ganancias basado en Botosan y Plumlee (2005). Con una muestra de 300 empresas enumeradas en B3 entre 2005 y 2014, se aplicaron las siguientes medidas de calidad de la información contable: persistencia, previsibilidad, accruals anormales, coeficiente de respuesta del resultado y value relevance con el fin de investigar si tienen diferencias en la capacidad de explicar la spread del exceso de rendimiento. Los resultados mostraron que todas las medidas de la calidad de la información contable, excepto la value relevance y los accruals anormales, se asociaron negativamente con la spread del exceso de rendimiento. Además, los accruals anormales fueron las métricas que representaron mejor la fijación errónea de precios de las acciones. Por lo tanto, como una implicación práctica, el presente estudio señala los accruals anormales, como las medidas de la calidad de la información contable que mejor observan la asimetría de información en el precio de las acciones en $B^{3}$.

Palabras clave: Calidad de la Información contable. Exceso de Retorno. Costo de capital. 


\section{Introdução}

Uma das funções principais da Contabilidade é a divulgação de informações profícuas sobre a entidade aos seus usuários, dado que parte é encaminhada ao público externo. Contudo, os usuários externos não deliberam sobre quais e como são escolhidos os critérios de avaliação da qualidade das informações divulgadas, além disso, não escolhem os auditores responsáveis pela análise das demonstrações contábeis que sintetizam os efeitos econômicos das operações das firmas. Dessa maneira, a qualidade da informação contábil tem forte relação com o contexto econômico, político e social na qual se insere a entidade (Paulo, 2007).

A objetividade na contabilidade não deve ser descreditada, razão pela qual a função do sistema contábil é fornecer informação útil aos investidores para a tomada de decisão. Entretanto, é percebido que em alguns quesitos é custoso desconsiderar os vieses individuais dos gestores e das firmas (BIERMAN, 1963). Consequentemente, é necessária mais objetividade nas técnicas e avaliações de mensuração dos componentes da informação contábil.

Neste sentido, o mercado de capitais gera oportunidade de destinar o capital poupado pelos investidores, e, portanto, faz-se atrativo ao investimento especialmente quando as empresas contidas nesse mercado divulgam de forma transparente a realidade das informações ocorridas. Dessa maneira, a transparência é atributo fundamental para reduzir a assimetria informacional, esta que seria um problema, pois, na maioria das vezes, conduz uma precificação não ótima (Girão, 2012).

No mesmo contexto, as pesquisas na área da qualidade da informação contábil têm como base os trabalhos de Dechow e Dichev (2002), isto é, os desenvolvedores do modelo de avaliação dos accurals, que são a fundação nos trabalhos de qualidade informacional de conteúdo contábil. Como consequência, Dechow, Ge e Schrand (2010) observaram o conteúdo de qualidade das informações e apuraram três fatos sobre as medidas de qualidade dos resultados: a relevância das informações, a informatividade dos números contábeis e se elas, as proxies, conseguem mensurar o desempenho.

O excesso de itens não publicados e a falta de transparência, em relatórios de contabilidade, estão relacionados com problemas na qualidade da informação contábil, mesmo estas apresentando-se em consonância com as normas contábeis vigentes. Portanto, é complexa a conceituação de qualidade de informação contábil a qual dependente dos objetivos dos seus usuários (Paulo, 2007). Por este motivo, se justifica a busca e utilização de diversas proxies para representar a qualidade dos números contábeis reportados pelas companhias. Perotti e Wagenhofer (2014) utilizaram o retorno em excesso como medida de assimetria informacional, já que em ambientes com informações distorcidas há uma alta probabilidade de haver má-precificação, o que leva a preços distorcidos e retorno excessivo, como resultado da má qualidade da informação contábil.

Assim posto, para medir a qualidade da informação contábil, Perotti e Wagenhofer (2014) fizeram uso de oito medidas da qualidade dos resultados, avaliando a persistência, previsibilidade (capacidade de inferir sobre os lucros em períodos seguintes), suavização dos lucros (gerenciamento de resultados), duas medidas de accruals e, por fim, duas de value relevance, estas que tratam do conteúdo informativo dos números contábeis.

Assim como Perotti e Wagenhofer (2014) apontaram, uma medida de qualidade da informação contábil é de maior qualidade quando consegue explicar, com mais precisão, as variações no retorno em excesso absoluto. A qualidade das informações afeta o nível de máprecificação, primeiramente porque empresas que relatam as informações financeiras com alta qualidade de lucro proporcionam informes mais precisos e transparentes aos investidores, e 
estes precificam as ações das empresas ocasionando uma menor má-precificação em relação as entidades possuidoras de uma qualidade inferior das informações contábeis. Consequentemente, uma menor qualidade das informações dos lucros resulta numa precificação menos precisa.

Diante dessa contextualização, fica o seguinte questionamento: qual a relação entre as medidas de qualidade da informação contábil, isto é, a persistência, previsibilidade, accruals anormais e value relevance, e a má-precificação das ações negociadas na $\mathrm{B}^{3}$ ?

Em vista disso, o objetivo desta pesquisa é observar a relação entre as medidas de qualidade da informação contábil, utilizando como métricas a persistência, previsibilidade, accruals anormais e value relevance, e a má-precificação das ações negociadas na $\mathrm{B}^{3}$ entre os anos de 2005 e 2014.

Para comparar as medidas de qualidade da informação contábil é necessário que se utilize um parâmetro de mensuração das próprias medidas, para tanto utilizou-se a máprecificação. Ocorre que a má-precificação se dá pela fraca qualidade da informação contábil que leva a erros na precificação, portanto, busca-se mensurar a má-precificação pelo retorno em excesso absoluto das firmas.

\section{Referencial Teórico}

\subsection{Qualidade da Informação Contábil}

A qualidade da informação contábil, atributo desejado num ambiente econômico, é reduzida pela assimetria de informação, porque esta diminui o conteúdo informacional evidenciado capaz de habilitar os agentes nas tomadas de decisão de investimento.

A assimetria informacional foi estudada pioneiramente por Akerlof (1970) na pesquisa Market for "Lemons". Ele explicou a assimetria de informação por meio do mercado de carros usados norte-americano. A assimetria se constituía no processo de compra e venda de automóveis usados, a partir do momento em que o detentor do veículo conhecia as suas condições e o comprador as desconhecia. Assim posto, o comprador, dado esse desequilíbrio informacional e, por desconhecer a situação do veículo, auferia um preço abaixo do que valeria o automóvel, sendo o veículo de qualidade, e, o portador do automóvel não venderia, pois estaria finalizando uma transação desfavorável (perda referente ao preço justo do automóvel).

A qualidade das informações contábeis foi extensivamente pesquisado na esfera nacional e internacional. No âmbito internacional, Dechow e Dichev (2002) propuseram uma medida de análise da qualidade de accruals e do lucro. A medida baseava-se no fato de que os accruals mudam ou se ajustam para reconhecer o fluxo de caixa ao longo do tempo, de modo que os números ajustados (e.g., lucros) mensurem com mais exatidão a performance das firmas.

No que diz respeito às características da qualidade das informações contábeis, Dechow et al. (2010) tratam de três. A primeira está condicionada à decisão relevante da informação, além disso, o termo earnings quality sozinho não atribui sentido. Em seguida, a qualidade dos lucros reportados está atrelada a capacidade de ser informativo sobre o desempenho financeiro da firma. E por fim, que a qualidade das informações contábeis é juntamente determinada pelo desempenho financeiro, que implicitamente está atrelada à decisão, e a habilidade do sistema contábil em mensurar a performance.

Duas atribuições relevantes da informação contábil no mercado de capitais foram ressaltadas por Beyer, Cohen, Lyz e Walther (2010). A primeira diz respeito a possibilidade de avaliar retornos potenciais de oportunidades de investimento, enquanto que a outra 
atribuição é que a informação contábil evidencia aos investidores e credores como os recursos disponíveis da entidade estão sendo utilizados.

Nesse sentido, os resultados correntes podem ser indicativos dos resultados futuros, isto é, eles podem apresentar capacidade de previsibilidade. A qualidade dos resultados, conforme Penman e Zhang (2002), tende a ser compreendida como as chances de que uma firma venha a ter os resultados correntes persistentes no futuro. Portanto, companhias com resultados mais persistentes apresentam lucros mais sustentáveis no futuro, podendo vir a torná-lo um elemento essencial e de utilidade para avaliar investimentos.

O nível da qualidade da informação contábil divulgada, das sociedades anônimas listadas na BM\&FBovespa entre 1996 e 2006 em ambientes empresariais competitivos, foi analisada por Almeida (2010). Foi aceita a hipótese de que quanto mais competitivo o mercado, maior o grau de conservadorismo, ou seja, a relação observada na pesquisa indicou que as empresas estão possivelmente adiantando as perdas econômicas futuras nos resultados.

Foi observado por Dichev, Graham, Harvey e Rajgopal (2013) que a literatura científica não conseguiu entrar num consenso sobre como mensurar a qualidade da informação contábil, pois várias são as métricas utilizadas nas pesquisas, como por exemplo: persistência e previsibilidade de lucros, suavização de resultados, reconhecimento de perdas assimétricas, intensidade dos accruals, accruals anormais discricionários.

Persistência, segundo Lima, Carvalho, Paulo e Girão (2015), é uma medida que prolonga ou auxilia a recorrência de resultados no futuro. Perotti e Wagenhofer (2014), relata que a presença de alta persistência pode indicar alta qualidade das informações contábeis, visto que por indicar estabilidade e menos volatilidade no processo de geração de resultado. Então, resultados persistentes são associados a previsões mais precisas de lucros sustentáveis no longo prazo (DICHEV et al., 2013).

Acredita-se que os resultados evidenciados nos demonstrativos financeiros são as principais métricas utilizadas para avaliar o desempenho das firmas pelos agentes econômicos externos à empresa. Isto posto, pode-se inferir que é proveitoso compreender os fatores que formam o resultado contábil (fluxo de caixa e accruals) assim como cada um desses elementos reage na presença dos diversos fatores institucionais e organizacionais (Paulo, 2007).

Portanto, a informação contábil quando apresenta qualidade pode proporcionar queda nos custos de capital (LEUZ; VERRECCHIA, 2000), diminuição da assimetria informacional entre a companhia e os investidores, e aumento da eficiência nas aplicações dos recursos (BIDDLE; HILARY, 2006).

O trabalho de Perotti e Wagenhofer (2014) buscou na literatura proxies para a qualidade das informações contábeis, visto que elas não são diretamente observáveis, e encontraram que boa parte delas são baseadas intuitivamente em conceitos desejados das características de um sistema contábil.

\subsection{Evidências Empíricas}

No tocante às evidências empíricas, foi analisada por Aboody, Hughes e Liu (2005) a relação entre as medidas qualidade da informação contábil com a assimetria de informação retratada no custo de capital das firmas, para tanto utilizou os modelos de Jones Dechow, Sloan e Swenney (1995) e dois modelos baseados em (DECHOW; DICHEV, 2002). Os resultados apontaram para uma relação fraca, porém consistente entre a qualidade da informação contábil e os efeitos nos preços resultante da assimetria. Portanto, Aboody et al. (2005) concluíram que o risco de informação assimétrica, mensurado pela exposição da firma aos fatores de qualidade dos resultados que mimetizam os portfólios, apresentam efeitos 
mensuráveis nos preços e o risco é positivamente associado com as expectativas de lucratividade dos insiders trading.

Os accruals são métricas utilizadas na relação da qualidade da informação contábil com a redução dos riscos de investimentos, nessa lógica Francis, Lafond, Olsson e Schipper (2005) relacionaram a qualidade dos accruals e o custo de capital de uma amostra de empresas norteamericanas durante o período de 1970 a 2001. Os resultados obtidos da pesquisa validaram que os accruals de pior qualidade estão associados a custos mais altos da dívida, maiores custos de capital próprio que refletem em preços mais baixos e riscos mais elevados (betas das empresas). Outro ponto atestado pelos autores foi de que qualidade de accruals pesa como um fator de explicação das variações do retorno em excesso quando utilizados modelos de precificação de ativos de dois e três fatores.

No Brasil, foi realizada uma pesquisa por Lopes (2009) que investigou a relação entre qualidade da informação contábil e os níveis de governança corporativa nas empresas brasileiras. Os resultados indicaram uma correlação entre conservadorismo condicional (reconhecem mais favoravelmente as perdas econômicas nos lucros) e nível de governança corporativa mais rígida, elevando a importância da informação contábil no mercado de ações.

Prosseguindo na perspectiva da qualidade dos resultados, com relação às métricas utilizadas Dechow, Ge e Schrand (2010) analisaram várias pesquisas de conteúdo referente à qualidade das informações contábeis, assim como as métricas mais utilizadas (Persistência, Magnitude dos accruals, resíduos dos modelos de accruals, suavização, reconhecimento oportuno da perda, coeficiente resposta e $\mathrm{R}^{2}$ do modelo de value relevance). Forneceu a teoria para cada uma, assim como os prós e contras. Os resultados evidenciaram que como as medidas de qualidade cuja variável é o lucro, dependem dos accruals e, consequentemente estes são a base da mensuração dos lucros, as medidas de qualidade são afetadas pelos fundamentos das firmas, como pela mensuração da performance.

Uma análise do impacto da International Financial Reporting Standards (IFRS) na qualidade da informação contábil nas firmas brasileiras e europeias, entre os anos de 2000 e 2011, foi realizada por Paulo, Carter, Girão e Souza (2013). Observaram a ocorrência de queda na persistência dos resultados nas empresas brasileiras após a adoção da IFRS, fato que pode ter sido agravado pela crise mundial iniciada em 2007. No que diz respeito ao conservadorismo, o mesmo foi observado, pois não houve diferença significativa entre os seus valores antes e depois da implantação da IFRS. Portanto, os autores concluíram que na média as adoções das IFRS não acrescentaram qualidade às informações contábeis.

De acordo com Perotti e Wagenhofer (2014), a literatura empírica considera qualidade de accruals a melhor medida em relação as medidas baseadas na contabilidade e por isso é utilizada nas pesquisas. Uma explicação para sua superioridade é a presença da estimação do fluxo de caixa um período a frente, fazendo com que essa medida agregue mais informação do que as outras. A medida baseada em mercado costumeiramente utilizada é value relevance, que é calculada pelo coeficiente resposta de lucro, representado pelo coeficiente da regressão de retorno de mercado em lucro. É argumentado que a medida de value relevance é melhor explicada pelo $\mathrm{R}^{2}$ da regressão (PEROTTI; \& WAGENHOFER, 2014).

O estudo feito por Paulo, Martins e Girão (2014) analisou a qualidade das informações contábeis divulgadas por empresas de capital aberto na América Latina e nos Estados Unidos entre 2005 e 2011. Para isso, os autores adotaram como medidas a persistência, conservadorismo, gerenciamento de resultados e accruals quality. Os resultados, preliminares, confirmaram os achados da literatura internacional empírica que dizem ser o lucro contábil mais persistente que o fluxo de caixa e, portanto, é sugerido que o lucro contábil pode ser mais útil que o fluxo de caixa para medir a performance das companhias Latino-Americanas, exceto para o Chile. Posteriormente, foi observado que, excetuando-se o Brasil, as Empresas 
Latino-Americanas são menos conservadoras do que as Norte-Americanas.

Foi analisado o impacto da adoção completa das IFRS na qualidade da informação contábil e no custo de capital próprio das companhias brasileiras por Silva e Nardi (2014). Os resultados demonstrados informam que a hipótese formulada pelo autor, aumento da qualidade do lucro após aceitação total da IFRS, não foi rejeitada, pois os atributos qualidade da informação contábil, gerenciamento de resultados, conservadorismo, value relevance - apontaram consequências favoráveis para a aceitação da teoria propostas pelos autores.

Nessa mesma linha de pesquisa, Santos, Filho e Klann (2014) avaliaram o impacto da convergência às IFRS na value relevance das informações contábeis demonstradas pelas empresas que negociam ações na BM\&FBovespa. Foram utilizadas medidas de preços explicados pelos lucros e lucro pelo retorno. Os resultados foram contraditórios, dado que em alguns casos como nos modelos que incluíam variáveis dummy para tratar os períodos pré, implantação e pós-convergência não foram significativas, enquanto o modelo de preços após seis meses apresentou estatística significativa, inferindo que a convergência às normas internacionais trouxe mais value relevance.

O comportamento da qualidade das informações contábeis, de acordo com Lima et al. (2015), são parcialmente explicados pelo ciclo de vida da empresa. Lima et al. (2015) adotaram as empresas listadas na BMF\&Bovespa classificadas em 19 setores durante os anos de 1995 e 2011. Como medidas de qualidade da informação contábil serviram-se do conservadorismo, persistência dos lucros operacionais, persistência dos fluxos de caixa e o gerenciamento de resultados.

Por conseguinte, verifica-se pelos estudos anteriores que as métricas da qualidade da informação contábil são utilizadas com diversos propósitos, principalmente como critério de identificação de atributos ou como elas se relacionam com suas consequências, isto é, com o custo de capital.

Sendo assim, dados os indícios de que as métricas possuem a capacidade de mensurar a qualidade, há de se investigar quão bem elas conseguem explicar o retorno em excesso quando mensurado com o custo de capital implícito pautado em Botosan e Plumlee (2005), haja vista este ser um fenômeno de interesse dos pesquisadores e do mercado.

Neste contexto, sugeridas as seguintes hipóteses de pesquisa:

H1: As medidas de qualidade da informação contábil são negativamente relacionadas com o valor do retorno em excesso.

H2: As medidas de qualidade da informação contábil distinguem-se na capacidade de discriminar firmas com alta e com baixa qualidade na informação contábil, mensurada pela diferença absoluta dos retornos em excesso.

\section{Metodologia}

\subsection{População e Amostra}

Esta pesquisa utilizou dados das empresas brasileiras não financeiras listadas na $\mathrm{B}^{3}$ (população) durante os anos de 2005 a 2014, visto que as informações necessárias dos lucros por ação fornecidas por meio das previsões dos analistas, disponíveis da base de dados da Thomson Reuters só apresentaram dados substanciais a partir desse ano. Os dados foram coletados na base de dados Thomson Reuters Eikon ${ }^{\circledR}$. Foram excluídas as firmas dos setores financeiros pelo fato da alta alavancagem financeira que provocariam interpretações enviesadas dessas firmas, como dificuldade financeira. Além de que a diferença resultante na mensuração dos accruals, dadas as diferenças de normas contábeis, conduziriam a problemas 
nos modelos utilizados.

\subsection{Medidas de Qualidade da Informação Contábil}

Foram utilizadas cinco (5) medidas de qualidade de informação contábeis, as quais são: persistência, previsibilidade, accruals anormais e duas medidas de value relevance. Vale ressaltar que todas as métricas da qualidade da informação contábil (equações (1), (4) e (5)) foram estimadas por modelos de regressão com dados em painel, em que foram verificados quais efeitos se ajustavam melhor, fixos ou aleatórios. Além disso, realizou-se os testes para verificar o problema de autocorrelação e heterocedasticidade, buscando corrigí-los no caso de presença de um deles em cada modelo.

A medida base de qualidade de resultado para a persistência e a previsibilidade escolhida foi lucro líquido antes de itens extraordinários ( $L L A E)$. As duas medidas de séries de tempo, persistência (QIC1) e previsibilidade (QIC2) são calculadas na seguinte equação (1) da regressão:

$$
L L A E_{i, t}=\propto+\beta L L A E_{i, t-1}+\varepsilon_{i, t},
$$

Em que: $L L A E$ é dividido pelo total de ativos no início do período $t$.

Desta forma, a Persistência (QIC1) é equivalente ao coeficiente de inclinação $\beta$ da regressão (1) que diz quanto do $L L A E$ do período passado consegue persistir no período presente, enquanto que Previsibilidade (QIC2) é o $\mathrm{R}^{2}$ da regressão (1), ou seja, quanto $L L A E$ do tempo $t$-1 está explicando o $L L A E$ do tempo presente.

No que diz respeito às métricas de qualidade da informação contábil baseadas em accruals, informa-se da necessidade de calcular os Accruals totais (AT). O AT é calculado conforme a equação (2) abaixo:

$$
A T=\triangle A C-\triangle P C-\triangle V C+\triangle D C P-D E P R
$$

Em que: $\triangle A C$ é a variação do ativo circulante; $\triangle P C$, variação do passivo circulante; $\triangle V C$, variação no caixa; $\triangle D C P$, variação de dívida de curto-prazo e; $D E P R$, depreciação do exercício no ano terminando em $t$. Quanto ao fluxo de caixa das operações $(F C O)$, ele é calculado da seguinte maneira da equação (3):

$$
F C O=L L A E-A T
$$

A medida accruals anormal (QIC3) baseada na medida tratada por Dechow et al. (1995) é estimada, respectivamente na regressão (4) da seguinte maneira:

$$
A T_{i, t}=\propto+\beta_{1}\left(\Delta R E C_{i, t}-\Delta C A R_{i, t}\right)+\beta_{2} I I E_{i, t}+\varepsilon_{i, t},
$$

Em que: $\triangle R E C$ é a variação na receita, $\triangle C A R$ a variação nas contas a receber, e $I I E$ são imóveis, instalações e equipamentos.

A medida de accruals anormais é o resíduo absoluto $\left|\varepsilon_{i, t}\right|$ multiplicado por (-1). Esta medida está relacionada com as distorções intencionais auferidas pelos gestores em aplicações das normas contábeis ou com intenção de gerenciar os resultados (DECHOW; GE; 
SCHRAND, 2010). Essa definição inclui a interpretação prévia de que altos valores de (QIC3), ou seja, valores próximos de 0 , indicam alta qualidade das informações contábeis.

Por fim, as duas medidas de value relevance são estimadas com base na equação da regressão (5):

$$
R E T_{i, t}=\propto+\beta \frac{L L A E_{i, t}}{P_{i, t}}+\varepsilon_{i, t}
$$

Em que: RET indica o retorno de doze meses que terminam quatro (4) meses após o fim do ano fiscal, para poder refletir, nos preços das ações, a divulgação dos números contábeis que ocorrem em até 4 meses do final do exercício fiscl; e $P_{i, t}$ é o valor de mercado da ação no início do período ano $t$.

A medida do coeficiente resposta de resultado (CRR) (QIC4) é o $\beta$ da equação (5), enquanto que a medida value relevance (QIC5) é o coeficiente de determinação $\left(\mathrm{R}^{2}\right)$ da regressão (equação 5). Ambas as métricas (QIC4) e (QIC5) podem ser interpretadas da seguinte forma: quanto maior os seus valores (coeficiente resposta de resultado ou coeficiente de determinação), maior a qualidade da informação contábil. A primeira, porque revela a magnitude da capacidade explicativa do $L L A E$ frente aos retornos; e a segunda, pelo fato de revelar a capacidade das variações do RET serem explicadas pelas variações das informações contábeis $(L L A E)$, demonstrando a relevância dos números contábeis.

\subsection{Retorno em Excesso e Custo de Capital Implícito}

O Retorno em excesso é calculado pela diferença entre o retorno realizado e o retorno esperado para um determinado período. Sendo assim, este trabalho se sustenta, para calcular o retorno esperado, na metodologia de Botosan (1997) e Botosan e Plumlee (2005). Elas investigaram diversas proxies para o cálculo do custo de capital e ponderaram que as metodologias com base nos dividendos descontados, o método formulado por Ohlson e Juettner-Nauroth (2005) e a metodologia dos crescimentos dos lucros, apresentaram resultados semelhantes e satisfatórios.

Dessa maneira, optou-se por utilizar, neste trabalho, o método de crescimento dos lucros pela simplicidade e pela capacidade de explicar o custo de capital, ambas observadas por Botosan e Plumlee (2005). Assim, esse método procede do modelo de valuation baseado nos informes contábeis de Ohlson e Juettner-Nauroth (2005) que, derivado algebricamente, resulta no custo de capital implícito.

O custo de capital implícito, portanto, utiliza-se dos fundamentos contábeis e oriundos das previsões dos analistas ao invés das informações de mercado, computando o CAPM, as quais estão relacionadas às expectativas dos agentes. Com base nessa abordagem, ele é retratado na equação (6) abaixo:

$$
r_{O J N}=A+\sqrt{A^{2}+\frac{l p a_{1}}{P_{0}} *\left(\frac{l p a_{2}-l p a_{1}}{l p a_{1}}-(\gamma-1)\right)}
$$

Em que: $r_{O J N}$ é o custo de capital calculado por meio da metodologia de Ohlson e Juettner-Nauroth (2005); $\gamma$ é o parâmetro de persistência; $l p a_{t}$ é o lucro por ação previsto para o ano $t$ com base nos analistas e $A$ é a equação (7). Neste caso assume-se que os dividendos por ação serão zero e $\gamma=1$, ou seja, não existe crescimento anormal de lucros no 
horizonte de previsão.

$$
A=\frac{1}{2}\left((\gamma-1)+\frac{d p a_{1}}{p_{0}}\right)
$$

Em seguida, é possível aproximar-se do custo de capital implícito baseado nos crescimentos dos lucros previstos pelos analistas para um horizonte de previsão de 2 anos à frente. Esse custo de capital é descrito na equação (8) abaixo:

$$
r_{P E G}=\sqrt{\frac{l p a_{2}-l p a_{1}}{P_{0}}}
$$

Consequentemente, o retorno em excesso de cada firma é o retorno anual menos o esperado $\left(r_{P E G}\right)$ :

$$
\operatorname{RETEX}_{i, t}=R_{i, t}-r_{P E G}
$$

Em que: o $R E T E X_{i, t}$ é o Retorno em excesso percentual anual $(t)$ da firma $i$. Em seguida, será realizada duas abordagens para associar as medidas de qualidade da informação contábil com o retorno em excesso.

\subsection{Testes estatísticos}

O primeiro método emprega uma abordagem de formação de portfólios com base nos quartis que é costumeiramente utilizada para analisar a rentabilidade em negociações com estratégias de hedge e a má-precificação das ações no mercado. As formações dos portfólios são feitas com bases em ponderações de quartis para as medidas de qualidade da informação contábil e para os retornos em excesso. Sendo assim, foram criados portfólios com base nas medidas de qualidade e no retorno em excesso anual.

Essa abordagem foi aplicada por Perotti e Wagenhofer (2014), que efetuou uma diferença entre o retorno em excesso médio absoluto na parte superior dos quartis (os $25 \%$ maiores retornos em excesso) da média do retorno em excesso absoluto das empresas da parte inferior dos quartis (os $25 \%$ inferiores retornos em excesso), para usar como proxy da medida de qualidade da informação contábil e, assim, será nomeada essa diferença de spread do retorno em excesso absoluto (AERS). Essa medida indica a magnitude da associação entre as medidas de qualidade da informação contábil e o retorno em excesso. Portanto, explora-se a magnitude de (AERS) como proxy para o conteúdo de informação das medidas de qualidade de informação contábil.

Em seguida, realizou-se Regressões Quantílicas (KOENKER \& BASSETT, 1978) associando as medidas de qualidade da informação contábil ao Spread do retorno em excesso absoluto (AERS), para medir o impacto da relação entre essas medidas. A metodologia de Regressão Quantílica é um método semi-paramétrico que toma como estimadores os quantis condicionais aos valores da variável dependente. É possível calcular todos os percentis relativos e analisar como cada parcela dos dados se comportaram ao longo do tempo, setores/firmas, ou os dois ao mesmo tempo (dados em painel). É um método que se apresenta bastante robusto à outliers e, consequentemente a problemas de Heterocedasticidade, pois ao 
contrário do método tradicional de regressão linear estimado por Ordinary Least Squares, o qual utiliza a média condicional, pode-se, na Regressão Quantílica, utilizar a mediana cujo sensibilidade à dados extremos é muito baixa (SANTOS, 2012; OHLSON; KIM, 2015).

\section{Resultados}

A amostra utilizada na pesquisa consistiu de empresas que negociam ações na $\mathrm{B}^{3}$, com exceção daquelas pertencentes ao setor financeiro tendo em vista a diferença no padrão contábil, durante os anos de 2004 a 2014. Durante o processo de ajuste dos dados, foi necessário excluir as informações faltantes, resultando, ao final, 300 empresas e 949 observações durante todo o lapso temporal. Sendo assim, este trabalho apresenta como primeiro resultado as estatísticas descritivas, exposta na tabela 1, das principais variáveis contábeis utilizadas para computar as medidas de qualidade da informação contábil.

Como é possível observar, na tabela 1 , as médias de todas as variáveis relatadas são heterogêneas, uma vez que estão em níveis distintos e, portanto, não são passíveis de comparação em primeira análise. O desvio-padrão de todas as variáveis é elevado, ou seja, um indicativo de grande dispersão dos dados que torna a amostra heterogênea e sugestiva de apresentar o problema de heterocedasticidade. Os percentis demonstram entre si uma alta variabilidade, o que foi observado no desvio-padrão, sendo assim o intervalo interquartílico, que é a diferença entre o quartil $75 \%$ pelo quartil $25 \%$, representou valores em níveis distintos tanto da média como do desvio-padrão.

De acordo com essas informações apresentadas na tabela 1 e, acrescentando o que é exposto na tabela 2, é perceptível que, as principais variáveis e algumas medidas de qualidade da informação contábil (por exemplo, QIC2, QIC3 e QIC5) são assimetricamente distribuídas, além de possuírem valores extremos em seus percentis. Ressalta-se que foram realizados os testes de heterocedasticidade e autocorrelação no processo de estimação das métricas e, em seguida, foram feitas as correções devidas para controlar os problemas estatísticos. Resultados semelhantes foram relatados por Perotti e Wagenhofer (2014) e, com isso, ele utilizou a formação de portfólios para mitigar os efeitos dos outliers. Seguindo essa linha, esta pesquisa fez o mesmo procedimento, formando portfólios por quartis.

Tabela 1: Estatísticas descritivas das principais variáveis

\begin{tabular}{ccccccccc}
\hline & $L L A E$ & \multicolumn{2}{c}{$F C O$} & \multicolumn{1}{c}{ AT } & IIE & \multicolumn{1}{c}{ AREC } & \multicolumn{1}{c}{$\Delta C A R$} & Ativos \\
\hline Média & 900019 & 964551 & -63665 & 7781867 & 7185 & 1,64 & 20300000 \\
Desvio-padrão & 3673105 & 17200000 & 16900000 & 37300000 & 14700000 & 3185,93 & 67400000 \\
$10 \%$ & 75487 & -677235 & -1292780 & 15032 & -1317890 & $-419,71$ & 1018679 \\
$25 \%$ & 54509 & -80391 & -315241 & 68764 & -12691 & $-33,07$ & 1978837 \\
$50 \%$ & 209987 & 228873 & 1480 & 658600 & 240003 & 21,28 & 4522781 \\
$75 \%$ & 639863 & 928708 & 323149 & 3954139 & 792674 & 142,82 & 13500000 \\
$90 \%$ & 1561947 & 2063492 & 1229421 & 13400000 & 3000676 & 490,41 & 31700000 \\
Intervalo interquartílico & 585354 & 1009099 & 638390 & 3885375 & 805365 & 175,89 & 11500000 \\
\hline
\end{tabular}

Fonte: Dados da Pesquisa. Notas: O número de observações da amostra foi de 949 que compreendeu os anos de 2004 a 2014. $L L A E$ é o lucro líquido antes de itens extraordinários; FCO é o fluxo de caixa operacional; $A T$ representa os accruals totais; IIE, os imóveis, instalações e equipamentos; $\triangle R E C$ é a variação na receita; $\triangle C A R$, a variação nas contas a receber e; Ativos, os ativos totais. Os valores 10\%, 25\%, 50\%, 75\% e 90\% representam os respectivos quantis e; Intervalor interquartílico é a diferença entre o quantil $75 \%$ pelo $25 \%$.

A tabela 3 apresenta a correlação de Pearson entre as medidas de qualidade da informação contábil. Os valores significativos se demonstraram positivas, com exceção da 
relação entre QIC1 (Persistência) e QIC3 (accruals anormais), e QIC3 e QIC5 (Value Relevance), os quais não apresentaram significância. A única relação negativa foi entre QIC2 (Previsibilidade) e QIC5, cujo valor foi de $-1,13 \%$, mesmo assim, foi um valor pequeno e não significativo estatisticamente. Perotti e Wagenhofer (2014) observaram resultados significativos nas correlações entre as medidas, no entanto a correlação entre a Previsibilidade e a Value Relevance foi positiva a $17,57 \%$. O desejável parâmetro de correlação observado entre as medidas é de um baixo valor (correlação fraca), haja vista, elas captam diferentes atributos econômicos (PEROTTI; WAGENHOFER, 2014).

Tabela 2: Estatísticas descritivas das medidas de qualidade da informação contábil

\begin{tabular}{clllll}
\hline & QIC1 & QIC2 & QIC3 & QIC4 & QIC5 \\
\hline Média & 0,9543 & 0,5924 & -3183806 & 0,0000 & 0,0277 \\
Desvio-padrão & 0,2296 & 0,2221 & 3192711 & 0,0000 & 0,0244 \\
$10 \%$ & 0,6172 & 0,2367 & -8382903 & 0,0000 & 0,0069 \\
$25 \%$ & 0,8463 & 0,5384 & -4508619 & 0,0000 & 0,0112 \\
$50 \%$ & 0,9830 & 0,6347 & -2248391 & 0,0000 & 0,0181 \\
$75 \%$ & 1,0989 & 0,7302 & -590938 & 0,0000 & 0,0341 \\
$90 \%$ & 1,2318 & 0,8112 & -257159 & 0,0001 & 0,0711 \\
\hline
\end{tabular}

Fonte: Dados da Pesquisa. Notas: QIC1 representa a medida de persistência; QIC2, a medida de previsibilidade; QIC3 os accruals anormais; QIC4, o coeficiente resposta de resultado, ou seja, o beta do modelo de value relevance e; QIC5 o $\mathrm{R}^{2}$ do modelo de value relevance. Os valores 10\%, 25\%, 50\%, 75\% e 90\% representam os respectivos quantis.

As correlações apontadas no trabalho de Perotti e Wagenhofer (2014) expuseram fortes níveis para as medidas de séries temporais (QIC1 e QIC2) no valor de 0,7519, enquanto nesta pesquisa (Tabela 3 ) os valores foram em proporções menores $(0,4583)$. De forma contrária, em seu trabalho, eles observaram uma correlação mais fraca entre as medidas baseadas no mercado (QIC4 e QIC5) na ordem de 0,4923, enquanto que, neste artigo, o valor foi de 0,7324 .

Tabela 3: Correlação entre as Medidas de Qualidade da Informação Contábil

\begin{tabular}{|c|c|c|c|c|c|}
\hline & QIC1 & QIC2 & QIC3 & QIC4 & QIC5 \\
\hline QIC1 & 1 & & & & \\
\hline QIC2 & $0,4583 * * *$ & 1 & & & \\
\hline QIC3 & 0,0508 & $0,1109 * * *$ & 1 & & \\
\hline QIC4 & $0,6755 * * *$ & $0,4 * * *$ & $0,4244 * * *$ & 1 & \\
\hline QIC5 & $0,6323 * *$ & $-0,0113$ & 0,0221 & $0,7324 * * *$ & 1 \\
\hline
\end{tabular}

Fonte: Dados da Pesquisa. Notas: QIC1 consiste na medida de qualidade da informação contábil conhecida como persistência; QIC2, previsibilidade; QIC3 são os accruals anormais; QIC4, o coeficiente resposta de resultado do modelo de value relevance e; QIC5 o $\mathrm{R}^{2}$ do modelo de value relevance. Os asteriscos indicam a significância do teste $\mathrm{t}$, em que *, **, *** representam a significância à $10 \%, 5 \%$ e $1 \%$.

Na tabela 4 iniciam-se os resultados das relações entre o spread das médias dos retornos excesso dos portfólios formados a partir das medidas de qualidade de informação contábil. A primeira hipótese de pesquisa, a qual tinha como afirmação a relação negativa entre as medidas de qualidade e o retorno em excesso, não pode ser rejeitada, uma vez que, na tabela 4, todas as medidas, com exceção da value relevance, apresentam uma relação negativa, dado que os valores do spread do retorno em excesso (AERS) são negativos e 
significativos. Resultados semelhantes foram relatados por Perotti e Wagenhofer (2014), com a diferença de que todos os testes foram significativos. Além disso, os autores utilizaram a suavização de lucros cuja relação com o retorno em excesso foi positiva. No entanto, a suavização de lucros não foi abordada no escopo desta pesquisa.

Tabela 4: Retorno em Excesso e as Medidas de Qualidade da Informação Contábil

\begin{tabular}{lcccc}
\hline & Alta QIC & Baixa QIC & AERS & Estatística-t \\
\hline QIC1 & 19,392 & 61,564 & $-42,172$ & $-6,51^{* * *}$ \\
QIC2 & 18,357 & 110,707 & $-92,350$ & $-9,75^{* * *}$ \\
QIC3 & 10,658 & 27,410 & $-16,753$ & $-1,17^{*}$ \\
QIC4 & $-14,256$ & 72,204 & $-86,460$ & $-10,74^{* * *}$ \\
QIC5 & 13,636 & 19,668 & $-6,033$ & $-1,315$ \\
\hline
\end{tabular}

Fonte: Dados da Pesquisa. Notas: QIC1 representa a medida de persistência; QIC2, a medida de previsibilidade; QIC3 os accruals anormais; QIC4, o coeficiente resposta de resultado, ou seja, o beta do modelo de value relevance e; QIC5 o $\mathrm{R}^{2}$ do modelo de value relevance. Alta QIC representa o valor do retorno em excesso do portfólio compreendido pelo terceiro quartil das medidas de alta qualidade da informação contábil, enquanto a Baixa QIC, o primeiro quartil do portfólio. AERS representa a diferença interquartílica entre a alta QIC pela baixa QIC. Os asteriscos indicam a significância do teste t, em que *, **, *** representam a significância à $10 \%$, $5 \%$ e $1 \%$.

As evidências mostradas na tabela 4, podem fornecer indícios para testar a segunda hipótese de pesquisa $\mathrm{H} 2$ (i.e., apontar capacidade das medidas de qualidade da informação contábil em captar as informações contidas na magnitude do $A E R S$ ) indicam que, em valores absolutos e significantes estatisticamente, a medida que capta com mais precisão a má precificação das ações é a Previsibilidade (QIC2) apresentando o valor, em absoluto, de 92,35. Em segundo lugar, aparece o coeficiente resposta de resultado (QIC4) com uma magnitude de 86,46, seguido da persistência (QIC1), $(42,17)$ e, em último lugar, os accruals anormais (QIC3) com um valor de 16,75 em absoluto.

Esses resultados mostram direções divergentes das observadas por Perotti e Wagenhofer (2014), visto que estes relataram maior magnitude da captação de informações pelas medidas accruals $(12,64)$ para os accruals anormais e menos para a qualidade dos accruals $(21,97)$, seguido pelas medidas de suavização de lucros $(9,47)$ e coeficiente resposta de resultado $(8,46)$.

Tabela 5: Estatística Descritiva do Spread do Retorno em Excesso

\begin{tabular}{lccccc}
\hline & AERS1 & AERS2 & AERS3 & AERS4 & AERS5 \\
\hline Média & $-42,172$ & $-92,350$ & $-16,753$ & $-86,460$ & $-6,033$ \\
Desvio-padrão & 103,749 & 108,959 & 122,619 & 117,464 & 56,015 \\
$25 \%$ & $-83,240$ & $-142,773$ & $-72,040$ & $-137,540$ & $-46,820$ \\
$50 \%$ & $-20,529$ & $-75,849$ & 16,018 & $-55,840$ & $-8,905$ \\
$75 \%$ & 29,037 & $-25,866$ & 66,706 & $-7,540$ & 29,139 \\
\hline
\end{tabular}

Fonte: Dados da Pesquisa. Notas: AERS1 representa o spread do retorno em excesso para a primeira medida de qualidade da informação contábil, Persistência, que é computado pela diferença da média do retorno em excesso para o terceiro quartil (Alta QIC) pela média do retorno em excesso do primeiro quartil (Baixa QIC). A numeração segue a ordem: 2 - Previsibilidade; 3 -Accruals anormais; 4 - coeficiente resposta de resultado; 5 Value Relevance.

As estatísticas descritivas do spread do retorno em excesso (AERS) são apresentadas, na tabela 5, por segregação de portfólios com base na diferença das altas e baixas medidas de qualidade de informação contábil. Percebe-se uma elevada variabilidade dos dados em 
comparação às medidas de qualidade de resultados. Além disso, todas as medidas se demonstraram assimétricas, uma vez que exibem considerável distanciamento de valores da média em relação à mediana, o que corrobora aind amais a necessidade de utilizar a regressão quantílica na mediana que é robusta. Em todas as medidas, com exceção da value relevance (QIC5) as médias são menores do que as medianas, ou seja, as distribuições são assimétricas à esquerda, indicando maior concentração dos dados em valores mais elevados.

Tabela 6: Interação por OLS entre os Spread dos Retornos em Excesso

\begin{tabular}{lccccc}
\hline & AERS1 & AERS2 & AERS3 & AERS4 & AERS5 \\
\hline AER1 & - & $-0,077$ & $0,080^{* * *}$ & $0,907 * * *$ & 0,016 \\
AERS2 & $-0,089$ & - & 0,082 & $-0,082$ & 0,035 \\
AERS3 & $-0,354 * * *$ & 0,080 & - & $-0,566^{* * *}$ & $0,084 * *$ \\
AERS4 & $0,748^{* * *}$ & $-0,063$ & $-0,546^{* * *}$ & - & $-0,083 * *$ \\
AERS5 & 0,067 & 0,125 & $0,358^{* *}$ & $-0,411 * *$ & - \\
\hline
\end{tabular}

Fonte: Dados da Pesquisa. Notas: AERS1 representa o spread do retorno em excesso para a primeira medida de qualidade da informação contábil, Persistência, que é computado pela diferença da média do retorno em excesso para o terceiro quartil (Alta QIC) pela média do retorno em excesso do primeiro quartil (Baixa QIC). A numeração segue a ordem: 2 - Previsibilidade; 3 -Accruals anormais; 4 - coeficiente resposta de resultado; 5 Value Relevance. Os asteriscos indicam a significância do teste t, em que *, **,*** representam a significância à $10 \%, 5 \%$ e $1 \%$.

A tabela 7 e 8 expõem, respectivamente interações por OLS e regressão quantílica na mediana, as diferenças de magnitude dos spreads do retorno em excesso entre as medidas de qualidade da informação contábil. Os valores apresentados são os coeficientes das relações entre as variáveis $A E R S$ das medidas de qualidade.

Tabela 7: Interação por regressão quantílica (mediana) entre os Spread dos Retornos em Excesso

\begin{tabular}{lccccc}
\hline & AERS1 & AERS2 & AERS3 & AERS4 & AERS5 \\
\hline AERS1 & - & $-0,027$ & $-0,307 * * *$ & $0,927 * * *$ & 0,008 \\
AERS2 & $-0,028$ & - & 0,036 & 0,009 & 0,009 \\
AERS3 & $-0,284 * * *$ & $0,130^{* *}$ & - & $-0,533^{* * *}$ & $0,093 * *$ \\
AERS4 & $0,770^{* * *}$ & $-0,031$ & $-0,488^{* * *}$ & - & $-0,080^{* *}$ \\
AERS5 & 0,238 & 0,053 & 0,240 & $-0,248$ & - \\
\hline
\end{tabular}

Fonte: Dados da Pesquisa. AERS1 representa o spread do retorno em excesso para a primeira medida de qualidade da informação contábil, Persistência, que é computado pela diferença da média do retorno em excesso para o terceiro quartil (Alta QIC) pela média do retorno em excesso do primeiro quartil (Baixa QIC). A numeração segue a ordem: 2 - Previsibilidade; 3 -Accruals anormais; 4 - coeficiente resposta de resultado; 5 Value Relevance. Os asteriscos indicam a significância do teste t, em que *, **,*** representam a significância à $10 \%, 5 \%$ e $1 \%$.

Os resultados da tabela 6 e 7 apontam, em valores absolutos, para um maior impacto da medida coeficiente resposta de resultado (QIC4) cujo AERS se relacionou, através de regressões por OLS e quantílica, mais fortemente, dada a maginitude dos coeficientes, com as outras medidas. Em segundo lugar, ficaram os accruals anormais (QIC3). As demais medidas (i.e., QIC1, QIC2 e QIC5) não apresentaram valores significativos entre si, apenas quando interagiram com as medidas referidas (i.e., QIC4 e QIC3). Vale ressaltar que esses resultados foram verificados tanto pelas estimações com OLS como por regressão quantílica na mediana e não divergiram apenas com significância na OLS para a medida de value relevance, contudo, esta medida não mostrou resultados significativos na tabela 4 . 
Diante dessas evidências, é conclusivo que a medida que melhor capta a magnitude da má precificação é o coeficiente resposta de resultado (i.e., coeficiente angular do modelo de value relevance), isso quando comparado com outras medidas, mesmo ela se posicionando em segundo lugar no primeiro teste. Porém, deu-se crédito à QIC4, pelo fato da medida com maior valor absoluto de $A E R S$ na tabela 4 (QIC2 - previsibilidade) não ser significativa nos testes da tabela 6 e 7, razão pela qual não foi estatisticamente significativa.

Em segundo lugar, é favorável atribuir a posição aos accruals anormais, os quais constataram significância em todos os testes e valores próximos da medida QIC4. Por conseguinte, Perotti e Wagenhofer (2014) alertaram para o fato de que os accruals fazem uso de uma maior quantidade de informações para serem estimados, logo podem aparentar mais precisão em relação a capacidade de captar a má-precificação das ações. Contudo, podem ocorrer problemas no processo de estimação dos parâmetros, pois os dados financeiros se apresentam heterogêneos.

No que tange aos modelos baseados no custo de capital implícito, eles têm mais impacto na capacidade relevante da informação contábil, de acordo com as evidências encontradas neste trabalho. Ou seja, utilizando-se das informações sobre lucros futuros, os analistas preveem com informações históricas e sobre as capacidades futuras das firmas de reportarem lucros relevantes.

\section{Considerações Finais}

O objetivo principal deste artigo foi estudar a relação entre as medidas de qualidade da informação contábil e o retorno em excesso no mercado brasileiros de capitais. Dentro dessa perspectiva, pautando-se metodologicamente no trabalho de Perotti e Wagenhofer (2014) no que tange a associação entre a qualidade da informação contábil e o spread do retorno em excesso, com a diferença no cálculo do retorno esperado, foi possível observar a semelhança da magnitude em relação aos accruals anormais, os quais constituem-se como uma medida capaz de captar as más-precificações das ações.

Isso pode implicar na escolha das métricas da qualidade da informação contábil no momento de realizar pesquisas com essa temática, pois no lugar de utilizar diversas métricas, seria possível optar por uma que capta melhor as dimensões qualitativas da informação contábil e, com base nas evidências desta pesquisa, sugere-se os accruals anormais como métrica da qualidade da informação contábil.

Utilizou-se da formação de portfólios, conforme Perotti e Wagenhofer (2014), para evitar efeitos indesejados, dadas as assimetrias das distribuições dos dados. Consequentemente, os resultados das proxies de qualidade da informação contábil foram segregados por quartis. Assim, as evidências mostraram uma relação negativa e significante entre o spread do retorno em excesso pelas medidas de qualidade de informação contábeis utilizadas neste trabalho, com exceção da value relevance a qual não demonstrou significância estatística, apenas uma relação negativa. Dessa maneira, foi possível testar a primeira hipótese de pesquisa deste artigo formulada sob a perspectiva dessa relação.

Para testar a segunda hipótese de pesquisa, diferentemente de Perotti e Wagenhofer (2014) que aplicaram testes de média, foram realizadas regressões por OLS como por Regressão Quantílica para observar as relações entre os spreads do retorno em excesso segregadas pelos portfólios das medidas de alta e baixa qualidade da informação contábil. Assim, a magnitude se demonstrou significante e expressiva entre as medidas de accruals anormais (QIC3) e coeficiente resposta de resultado (QIC4).

Dados esses resultados, esta pesquisa trouxe um avanço e contribuição metodológica na relação do spread do retorno em excesso com as métricas da qualidade da informação 
contábil, uma vez que empregou o custo de capital implícito no cálculo do retorno em excesso. Além disso, comparou as dimensões da qualidade da informação contábil no que diz respeito à sua capacidade de auxiliar o processo de tomada de decisões, haja vista ser esse um dos pilares da informação contábil (DECHOW et al. 2010). Consequentemente, verificou-se divergências em relação ao observado por Perotti e Wagenhofer (2014) quanto a capacidade das métricas em captar a má-precificação.

Nesse contexto, os resultados não podem ser integralmente comparados aos de Perotti e Wagenhofer (2014). Sob outro ponto de vista, esta pesquisa utilizou-se do custo de capital implícito, o qual toma como base as previsões dos analistas que se fundamentam nas informações contábeis das firmas, o que pode indicar menos sensibilidade as variações dos preços de mercado. Dessa forma, o custo de capital implícito se apresenta como uma métrica mais robustas às variações decorrentes das informações de mercado, podendo gerar melhores níveis de previsibilidade. Assim, pelo custo de capital implícito as precificações são fundamentadas pelas informações contábeis que servem de instrumento para os analistas preverem os valores das firmas, enquanto que, pelos modelos de precificação baseados em mercados, levam em conta a precificação esperada por flutuações nos preços e reações dos agentes do mercado às informações. Cabe investigar se existe essa diferença e se sim, é significativa.

Esse resultado encontrado pode ter sido em função da escolha das métricas do spread do retorno em excesso, que foi utilizado o modelo de Botosan e Plumlee (2005), assim podese afirmar, que para essa situação, os accruals anormais e o value relevance são as melhores medidas de qualidade da informação contábil.

Como contribuição teórica verifica-se que, dentre as dimensões qualitativas da informação contábil, os accruals anormais e o value relevance demonstram-se como as melhores representações da má-precificação das ações. Essa capacidade da informação contábil amplamente discutida por Dechow et al. (2010), pauta-se na capacidade da informação contábil em representar a situação econômico-financeira das companhias, tendo em conta que o seu papel é reduzir a assimetria informacional e auxiliar o processo de tomada de decisão dos agentes.

Sugere-se realizar novos estudos envolvendo outras métricas envolvendo o custo de capital implícito, tais como: previsão dos analistas, anomalias do mercado, e outras variáveis financeiras utilizadas pela literatura

Esta pesquisa limitou-se por não explorar todas as medidas de qualidade da informação contábil, além de não utilizar os modelos de precificação por três fatores de Fama e French no computo do custo de capital.

\section{Referências}

ABOODY, D.; HUGHES, J.; LIU, J. Earnings Quality, Insider Trading, and Cost of Capital. Journal of Accounting Research, v. 43, n. 5, 2005. https://doi.org/10.1111/j.1475679X.2005.00185.x

ALMEIDA, J. E. F. Qualidade da informação contábil em ambientes competitivos. Tese (Doutorado em Ciências Contábeis) - Faculdade de Economia, Administração e Contabilidade, Universidade de São Paulo, São Paulo, SP, 2010.

AKERLOF, G. A. The Market for 'lemons': quality uncertainty and the market mechanism. Quarterly Journal Economics, v. 84, n. 3, p. 488-500, 1970. https://doi.org/10.1016/B978$0-12-214850-7.50022-\mathrm{X}$ 
BEYER, A.; COHEN, D. A.; LYZ, T, Z.; WALTHER, B. R. The financial reporting environment: review of the recent literature. Journal of Accounting and Economics, v. 50, n. 2-3, p. 296-343, 2010. https://doi.org/10.1016/j.jacceco.2010.10.003

BIERMAN, H. Jr. Measurement and accounting. The Accounting Review, v. 38, n. 3, p. 501-507, 1963.

BIDDLE, G. C.; HILARY, G. Accounting quality and firm-level capital investment. The Accounting Review, v. 81, n. 5, p. 963-982, 2006. https://doi.org/10.2308/accr.2006.81.5.963

BOTOSAN, C. A. Disclosure Level and the Cost of Equity Capital. The Accounting Review, v. 72, n. 3, p. $323-349,1997$.

BOtOSAN, C. A.; PLUMLEE, M. Assessing Alternatives Proxies for the Expected Risk Premium. The Accounting Review, v. 80, n.1, p. 21-53, 2005.

DECHOW, P.; DICHEV, ILIA D. (2002). The quality of accruals and earnings: the role of accrual estimation errors. The Accounting Review, v. 77, n.4, p. 35-59, 2002.

DECHOW, P. M.; GE, W.; SCHRAND, C. Understanding earnings quality: a review of the proxies, their determinants and their consequences. Journal of Accounting and Economics, v. 50, p. 344-401, 2010. https://doi.org/10.1016/j.jacceco.2010.09.001

DECHOW, P.; SLOAN; R.; SWEENEY, A. (1995). Detecting Earnings Management. The Accounting Review, v. 70, p. 193-226, 1995.

DICHEV, I. D.; GRAHAM, J. R.; HARVEY, C. R.; RAJGOPAL, S. Earnings quality: evidence from the field. Journal of Accounting and Economics, v. 56, p. 1-33, 2013.

FRANCIS, J., LAFOND, R.; OLSSON P. M.; SCHIPPER, K. S. The Market Pricing of Accruals Quality. Journal of Accounting and Economics, v. 39, n. 2, p. 295-327, 2005.

GIRÃO, L. F. A. P. (2012). Assimetria informacional, insider trading e avaliação de empresas: evidências no mercado de capitais brasileiro. Dissertação (Mestrado em Contabilidade) - Programa Multiinstitucional e Inter-Regional de Pós-Graduação em Ciências Contábeis UNB/ UFRN/ UFPB, João Pessoa, PB, 2012.

LEUZ, C.; VERRECCHIA, R. E. The economic consequences of increased disclosure. Journal of accounting research, v. 38, n. 3, p. 91-124, 2000.

LIMA, A. S.; CARVALHO, E. V. A.; PAULO, E.; GIRÃO, L. F. A. P. Estágios do Ciclo de Vida e Qualidade das Informações Contábeis no Brasil. Revista de Administração Contemporânea, v. 19, n.3, p. 398-418, 2015.

LOPES, A. B. The relation between firm-specific corporate governance, cross-listing and the informativeness of accounting numbers in Brazil. Thesis in Manchester Business School, University of Manchester, 2009. 
OHLSON, J. A.; JUETTNER-NAUROTH, B. E. Expected EPS and EPS Growth as Determinants of Value. Review of Accounting Studies, 10, 2005.

OHLSON, J. A.; KIM, S. Linear Valuation Without OLS: The Theil-Sen Estimation approach. Review Accounting Studies, v. 20, p. 395-435, 2015.

PAULO, E. Manipulação das Informações Contábeis: Uma Análise Teórica e Empírica sobre os modelos operacionais de detecção de gerenciamento de resultados. Tese (Doutorado em Ciências Contábeis) - Faculdade de Economia, Administração e Contabilidade, Universidade de São Paulo, São Paulo, SP, 2007.

PAULO, E.; CARTER, D.; GIRÃO, L. F. A. P.; SOUZA, R. S. The Impact of the adoption of Internacional Financial Reporting Standards about The Quality of Accounting Information of the Brazilian and European Public Firms. IN: Anais do Congresso ANPCONT, 2013, Fortaleza, CE, Brasil, 7, 2013.

PAULO, E.; MARTINS, E.; GIRÃO, L. F. A. P. ACCOUNTING INFORMATION QUALITY IN LATIN and North-American Public Firms. In: Claúdio de Araújo Wanderley; Fábio Frezatti. (Org.). Accounting in Latin America. 1. ed.: Emerald, 14, p.1-39, 2014.

PENMAN, S. H.; ZHANG, X-J. Accounting conservatism, the quality of earnings and stock returns. The Accounting Review, v. 77, n. 2, p. 237-264, 2002.

PEROTTI, P.; WAGENHOFER, A. Earnings Quality Measures and Excess Returns. Journal of Business Finance \& Accounting, p. 545-571, 2014.

SANTOS, B. R. Modelos de Regressão Quantílica. Dissertação (Mestrado em Ciências) Instituto de Matemática e Estatística, Universidade de São Paulo, São Paulo, SP, 2012.

SANTOS, A. C.; FILHO, L. S.; KLANN, R. C. Efeitos do processo de convergência às normas internacionais de contabilidade no value relevance das demonstrações contábeis de organizações brasileiras. Revista Contemporânea de Contabilidade, v. 11, n. 22, p. 95-118, 2014.

SILVA, R. L. M.; NARDI, P. C. C. Full Adoption Of Ifrs In Brazil: Earnings Quality and Cost of Equity Capital. Working Paper, Social Science Research Network, 2014. 